\title{
ATIVIDADE AMILOLÍTICA E QUALIDADE FISIOLÓGICA DE SEMENTES ARMAZENADAS DE MILHO SUPER DOCE TRATADAS COM ÁCIDO GIBERÉLICO ${ }^{1}$
}

\author{
CARLOS ALBERTO ARAGÃO², BÁRBARA FRANÇA DANTAS ${ }^{3}$, ELZA ALVES $^{2}$, ANA CATARINA CATANEO4 \\ CLÁUDIO CAVARIANI ${ }^{5}$, JOÃO NAKAGAWA ${ }^{5}$
}

\begin{abstract}
RESUMO - O uso de reguladores de crescimento na fase de germinação melhora o desempenho das plântulas, acelerando a velocidade de emergência e realçando o potencial das sementes de várias espécies, mesmo sob condições adversas. Este trabalho teve como objetivo avaliar a influência do ácido giberélico na atividade amilolítica e no vigor de sementes armazenadas de milho super doce. O experimento foi conduzido nos Laboratórios de Análise de Sementes do Departamento de Produção Vegetal/FCA e no Laboratório de Bioquímica de Plantas do Departamento de Química e Bioquímica/IB da Universidade Estadual Paulista (UNESP/Botucatu), entre os meses de julho e setembro de 2001, onde foram feitas as avaliações da qualidade fisiológica, através dos testes de germinação, vigor e bioquímicos. Sementes de milho super doce da cultivar DO-04, foram acondicionadas em sacos de papel e armazenadas por oito meses em câmara seca (40\% UR). Após este período, foram colocadas para germinar em rolos de papel toalha, embebidos

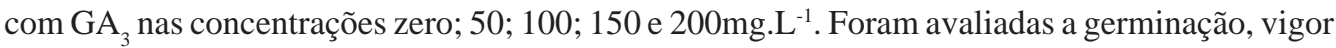
e atividade amilolítica das sementes. As sementes submetidas à pré-embebição em solução de 50mg. $\mathrm{L}^{-1}$ de ácido giberélico, apresentaram maior germinação e vigor, menor teor de proteínas totais e maior atividade amilolítica.
\end{abstract}

Termos para indexação: biorreguladores, Zea mays, milho doce, $\alpha$-amilase.

\section{AMYLOLITC ACTIVITY AND PHYSIOLOGYCAL QUALITY OF STORED SWEET CORN SEEDS TREATED WITH GIBBERELLIC ACID}

\begin{abstract}
The plant growth regulators use in seed germination improve the seedling field performance and accelerate the emergence speed and enhance seed potential in various species, even under stressing conditions. The objective of this study was to evaluate the effect of gibberellic acid on stored sweet corn seed vigor and amylolitic activity. The experiment was carried out at the Seed Analysis Laboratory of the Plant Production Department and at the Plant Biochemistry Laboratory of the Chemistry and Biochemistry Department, at the Universidade Estadual Paulista (UNESP/Botucatu), from July to September/2001, when evaluations of seed physiological quality were obtained by germination, vigor and biochemical tests. Super sweet corn seeds cultivar DO04 were placed in paper bags and stored for eight months in a dry chamber ( $40 \% \mathrm{RU})$. After that, the seed were germinated on paper towels imbibed in zero; 50; 100; 150 e $200 \mathrm{mg} . \mathrm{L}^{-1} \mathrm{GA}_{3}$ solutions. The seed germination, vigor and amylolitic activity were evaluated. Seeds pre-imbibed in GA 50mg. $\mathrm{L}^{-1}$ solutions showed improved germination and vigor, as well as lower protein content and higher amylase activity.

Index terms: bioregulators, Zea mays, sweet corn, $\alpha$-amylase.
\end{abstract}

\footnotetext{
${ }^{1}$ Aceito para publicação em 24.05.2003.

${ }^{2}$ Eng $^{\circ}$ Agr $^{\circ}$, Dr., Prof., DTCS, UNEB, Juazeiro-BA; e-mail: carlosaragao@hotmail.com

${ }^{3}$ Eng $^{\circ}$ Agr $^{\circ}$, Dra., Pesquisadora, Embrapa Semi-Árido, Cx. Postal 23, 56300970, Petrolina-PE; email:barbara@cpatsa.embrapa.br
}

\footnotetext{
${ }^{4}$ Bióloga, Dra., Profa. Departamento de Química e Bioquímica IB/UNESP, Botucatu-SP

${ }^{5}$ Eng $^{\circ}$ Agr $^{\circ}$, Dr., Prof. Departamento de Produção Vegetal FCA/UNESP, Botucatu-SP.
} 


\section{INTRODUÇÃO}

Com a expansão de mercado de milho doce no Brasil é necessária uma maior preocupação com a qualidade fisiológica das sementes empregadas. Além disso, é importante entender as alterações metabólicas que levam a sua deterioração ao longo do tempo.

Por conterem elevados teores de açúcares solúveis e baixo teor de reservas no endosperma, associados à presença de pericarpo tenro, sementes de milho doce, apresentam rápida perda da viabilidade, acarretando a baixa uniformidade do 'stand'. Esses fatores que tem levado a adoção de padrões de germinação destas sementes para 70\% e 75\%, respectivamente para sementes fiscalizadas e certificadas, em vez de $85 \%$, para ambas classes do milho comum no estado de São Paulo (CESM, 1999).

A preservação da qualidade das sementes durante o armazenamento, ou seja, da colheita até a sua utilização é um aspecto fundamental a ser considerado no processo produtivo, pois os esforços despendidos na produção podem não ser efetivos se a qualidade de sementes não for mantida, no mínimo, até a época da semeadura (Oliveira et al., 1999). Nas regiões tropicais e subtropicais, os danos causados pelas condições climáticas, durante o período de armazenamento, podem levar a perdas apreciáveis (Carvalho, 1992).

As manifestações da deterioração de sementes podem ser consideradas fisiológicas, metabólicas ou bioquímicas. Segundo Toledo e Marcos-Filho (1977), a queda do poder germinativo e do vigor das sementes é a manifestação mais acentuada da deterioração.

Técnicas que induzem a maior germinação e qualidade fisiológica são fatores importantes para aumentar o potencial de desempenho das sementes e, por conseguinte, a uniformidade das plantas em condições de campo. A embebição de sementes em substrato contendo solução com substâncias promotoras de crescimento, consiste em uma técnica bastante conhecida há vários anos. Tem sido demonstrado que os efeitos benéficos deste tratamento permanecem mesmo após a secagem das sementes (Rosseto et al., 2000).

$\mathrm{O}$ uso de reguladores de crescimento na fase de germinação melhora o desempenho das plântulas, acelerando a velocidade de emergência e realçando o potencial das sementes de várias espécies. Segundo Khan et al. (1978), o uso de compostos químicos biologicamente ativos, como reguladores de crescimento, pode cessar ou diminuir o impacto de fatores adversos na qualidade e desempenho das sementes. $\mathrm{O}$ uso de giberelinas na fase de germinação pode melhorar a performance de sementes de várias espécies, principalmente sob condições adversas (Bevilaqua et al., 1993; Cunha \& Casali, 1989).

As giberelinas têm papel chave na germinação de sementes, estando envolvidas tanto na superação da dormência como no controle de hidrólise das reservas, pela indução da síntese de novo da $\alpha$-amilase, enzima responsável pela hidrólise do amido. O ácido giberélico, considerado ativador enzimático endógeno, promove a germinação (Levitt, 1974), e a aplicação exógena deste promotor influencia o metabolismo proteíco, podendo dobrar a taxa de síntese de proteínas das sementes (Mc Donald \& Khan, 1983).

Segundo Salisbury \& Ross (1991), na maioria das espécies, as giberelinas atuam no alongamento celular, fazendo com que a raiz primária rompa os tecidos que restringem o seu crescimento, como o endosperma, o tegumento da semente ou estruturas do fruto. Em sementes de alface, colocadas para germinar em condições de escuro a $20^{\circ} \mathrm{C}$, o ácido giberélico estimulou a germinação das mesmas, quando submetidas a concentrações de 25; 50; 100 e 200mg.L - $^{-1}$ (Cunha \& Casali, 1989).

O presente trabalho teve como objetivo avaliar os efeitos do ácido giberélico na germinação de sementes armazenadas de milho super doce no vigor de plântulas e as alterações fisiológicas e bioquímicas decorrentes dos tratamentos.

\section{MATERIAL E MÉTODOS}

O trabalho foi realizado nos Laboratórios de Análise de Sementes do Departamento de Produção Vegetal/FCA e de Bioquímica de Plantas do Departamento de Química e Bioquímica/IB da Universidade Estadual Paulista de Botucatu, entre os meses de julho e setembro de 2001. Foram utilizadas sementes de milho super doce da Cultivar DO-04, retidas em peneiras 22. Essas sementes provenientes da safra 1999/2000, foram tratadas com fungicida e inseticida, acondicionadas em sacos de papel e em seguida armazenadas em câmara seca ( $40 \%$ UR, $25^{\circ} \mathrm{C}$ ), durante oito meses.

Os tratamentos constaram da germinação das sementes em rolos de papel toalha, embebidos com $\mathrm{GA}_{3}$ nas concentrações zero; 50; 100; 150 e 200 $\mathrm{mgL}^{-1}$. Foram semeadas 200 sementes de cada unidade experimental, em quatro subamostras de 50 sementes, em rolo de papel toalha "germitest" umedecido com quantidade de solução equivalente a 2,5 vezes o peso do substrato e mantidas em germinador a $25{ }^{\circ} \mathrm{C}$. As avaliações foram feitas aos quatro e sete dias após a semeadura e os resultados expressos em porcentagem 
média de plântulas normais; plântulas anormais - realizada em conjunto com a germinação, procurou-se identificar os seguintes tipos anormalidades de plântulas: sem raiz seminal, sem parte aérea, curta e fraca; sementes mortas - após o período do teste de germinação, as sementes que não apresentaram emissão da raiz primária foram então classificadas como mortas, as que apesar de passarem pelo processo de embebição, não germinaram; atividade amilolítica - para os testes bioquímicos 25 sementes de cada tratamento (zero; 50; 100; 150 e 200mg de $\mathrm{GA}_{3}$ por $\mathrm{L}^{-1}$, foram colocadas para germinar em gerbox, sobre duas camadas de papel germibox embebidos com a solução de GA, em germinador a temperatura de $25^{\circ} \mathrm{C}$. Após o quarto dia da semeadura foram retirados os eixos embrionários (raiz e parte aérea) restando apenas o pericarpo e endosperma, que foram congelados em nitrogênio líquido e). armazenados a $-20^{\circ} \mathrm{C}$. A extração das enzimas amilolíticas, assim como os ensaios de atividade foram realizados conforme método descrito por Gugelmineti et al. (1995). Os endospermas foram macerados com almofariz e pistilo em tampão TRIS-HCl 0,1mol. $\mathrm{L}^{-1}$, pH 7, contendo $\mathrm{NaCl}$ 0,1 $\mathrm{mol} \cdot \mathrm{L}^{-1} \mathrm{e} \mathrm{CaCl}_{2}$ 10mmol.L $\mathrm{L}^{-1}$. Essa solução foi centrifugada a $12.000 \mathrm{~g}, 4^{\circ} \mathrm{C}$ durante 10 minutos, coletandose o sobrenadante que foi congelado a $-20^{\circ} \mathrm{C}$ até a realização dos ensaios. A atividade de amilases totais e de $\alpha$-amilase foi medida em um sistema de reação, contendo tampão de reação (Acetato de sódio 50mmol.L-1 ${ }^{-1} \mathrm{pH} 5,2$ e $\mathrm{CaCl}_{2}$ $10 \mathrm{mmol} . \mathrm{L}^{-1}$ ) e amido solúvel de batata 2,5\% como substrato. Esse sistema de reação foi incubado a $35^{\circ} \mathrm{C}$ durante 15 minutos. Para inativar as outras amilases, permanecendo apenas a a-amilase, o extrato cru foi mantido a $70^{\circ} \mathrm{C}$, durante 15 minutos antes da realização do ensaio. Ao final do ensaio os açúcares redutores foram dosados pelo método do ácido dinitrosalicílico (DNS), em espectrofotômetro a 540nm. As atividades de amilases totais e amilases foram expressas em mmol de açúcares redutores produzidos pela degradação de amido, por mg de proteína, por minuto; determinação da quantidade de proteínas totais - foi realizada de acordo com o método proposto por Lowry et al. (1951), a partir da curva padrão de BSA (albumina bovina sérica) com leitura em espectrofotômetro a 660nm.

Os dados referentes aos efeitos dos fatores estudados nas características avaliadas foram analisados e apresentados por meio de análise de regressão, sendo selecionado para expressar o comportamento de cada característica o modelo significativo que apresentou maior coeficiente de determinação.

\section{RESULTADOS E DISCUSSÃO}

Na Figura 1, encontram-se os valores médios estimados de germinação, em função das doses de ácido giberélico $\left(\mathrm{GA}_{3}\right)$ aplicados ao papel de germinação. Observa-se que as sementes tratadas com 50 e $100 \mathrm{mg}^{-L^{-1}}$ de GA tiveram um ligeiro efeito favorável na germinação, quando comparada ao tratamento testemunha. Esses tratamentos proporcionaram acréscimos na germinação na ordem de $11 \%$ e $10 \%$, respectivamente. Resultados semelhantes foram encontrados por Aragão et al. (2001), trabalhando com sementes novas de milho doce com poder germinativo de 75\%, padrões da CESM (1999). Bevilaqua et al. (1993) e Vieira et al. (1998) detectaram aumentos na porcentagem de germinação de sementes de braquiarão e arroz, respectivamente, à medida que se aumenta a concentração de acido giberélico.

À semelhança do que ocorreu com a germinação final das sementes (Figura 1), observa-se novamente que o tratamento de 50mg. $\mathrm{L}^{-1} \mathrm{de} \mathrm{GA}_{3}$, proporcionou maior vigor representado pela primeira contagem do teste de germinação, indicando melhor qualidade fisiológica das sementes (Figura 2). As sementes de milho doce não tratadas mantiveram em média valores de $36 \%$ e $26 \%$ de germinação final e primeira contagem do teste de germinação, enquanto que as sementes tratadas com 50 mg. $\mathrm{L}^{-1}$ de $\mathrm{GA}_{3}$ apresentaram, aproximadamente, $40 \%$ e $30 \%$ de germinação final e primeira contagem, respectivamente (Figuras 1 e 2).

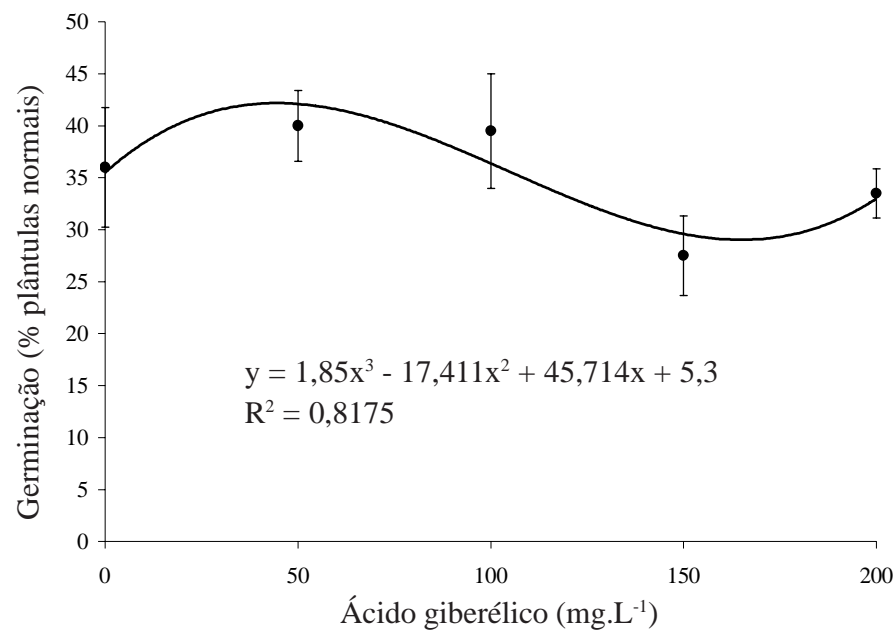

FIG. 1. Resultados médios da germinação de sementes (\%) armazenadas de milho super doce, submetidas a doses crescentes de ácido giberélico (Botucatu, 2001). 


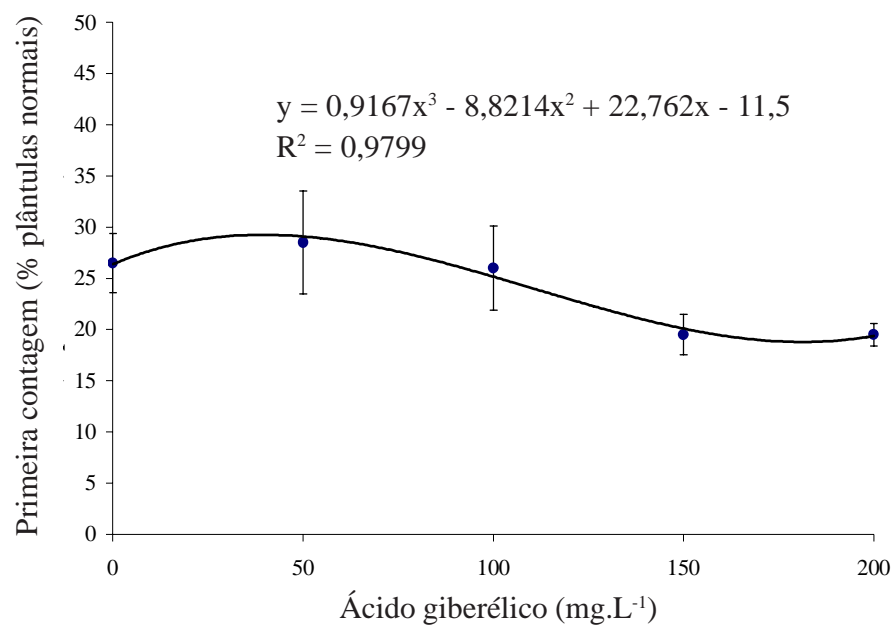

FIG. 2. Resultados médios da primeira contagem da germinação de sementes (\%) armazenadas de milho super doce, submetidas a doses crescentes de ácido giberélico (Botucatu, 2001).

Leonel \& Rodrigues (1996) trabalhando com sementes de limoeiro-cravo, obtiveram maior germinação com o emprego de 50mg.L ${ }^{-1}$ de $\mathrm{GA}_{3}$ e Bevilaqua et al. (1998), verificaram que sementes de cenoura tratadas com 100mgL-1 de $\mathrm{GA}_{3}$, apresentaram maior vigor em relação àquelas que não haviam sido tratadas.

Nagao \& Furutani (1986), relataram um aumento de 50\% na taxa de germinação de sementes de mamão papaya tratadas com $\mathrm{GA}_{3}$, instaladas em sementeiras. Vários outros autores também verificaram o efeito benéfico de pré-embebição pela imersão direta das sementes em solução contendo ácido giberélico (Rosseto et al., 2000).

A partir de $100 \mathrm{mg} . \mathrm{L}^{-1}$ de GA, houve uma queda na germinação e primeira contagem do teste de germinação (Figuras 1 e 2). Foi verificado também que sementes tratadas com concentrações de $\mathrm{GA}_{3}$ superiores a $100 \mathrm{mg} . \mathrm{L}^{-1}$ apresentaram um aumento acentuado no número de anormalidades de plântulas, indicando um possível efeito fitotóxico do ácido (Figura 3). Esse efeito também foi observado quanto ao número de sementes mortas (Figura 4). Rosseto et al. (2000), constataram que sementes de maracujá-doce escarificadas e tratadas com 300 $\mathrm{mgL}^{-1}$ de $\mathrm{GA}_{3}$ tiveram um acréscimo significativo na germinação. Por outro lado o número de plântulas anormais também aumentou, confirmando o efeito fitotóxico induzido pelo ácido em concentrações elevadas.

Verifica-se um decréscimo nos teores de proteínas totais nos tratamentos com 50, 100 e $150 \mathrm{mgL}^{-1}$ de $\mathrm{GA}_{3}$, respectivamente (Figura 5). O baixo teor de proteínas totais pode ser

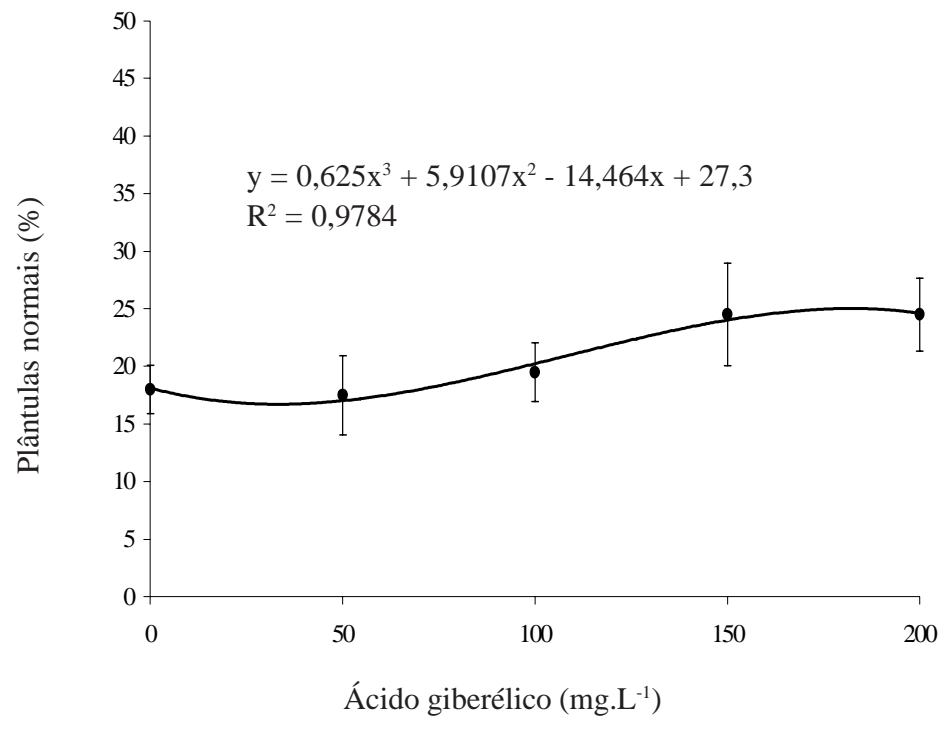

FIG. 3. Resultados médios da porcentagem de plântulas anormais (\%) do teste de germinação de sementes armazenadas de milho super doce, submetidas a doses crescentes de ácido giberélico (Botucatu, 2001).

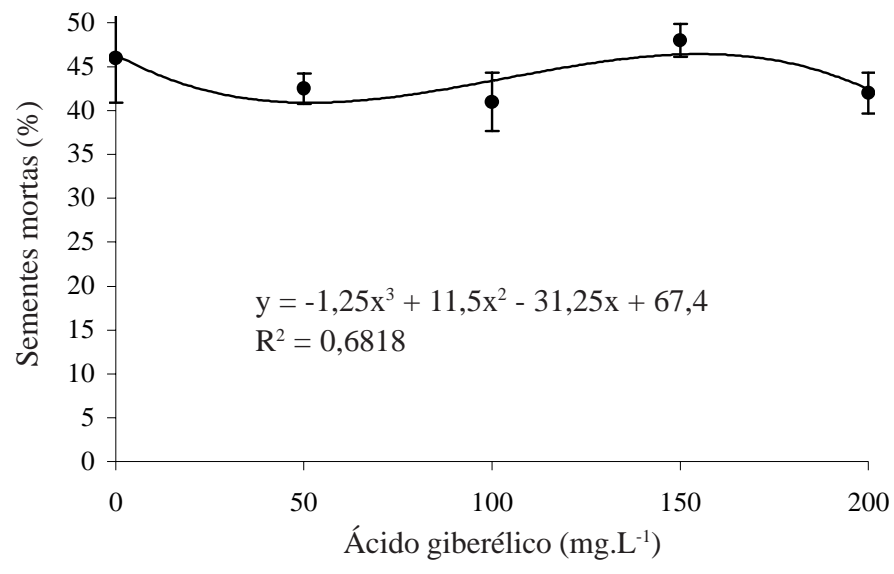

FIG. 4. Resultados médios da porcentagem de sementes mortas (\%) do teste de germinação de sementes armazenadas de milho super doce, submetidas a doses crescentes de ácido giberélico (Botucatu, 2001).

explicado pela degradação das proteínas de reserva existentes nas sementes quiescentes, disponibilizando aminoácidos para a síntese de novas proteínas, sendo elas de função estrutural ou enzimática (Mayer \& Poljakoff-Mayber, 1985). Entre as enzimas sintetizadas, aquelas de degradação de reservas como as amilases, são as mais importantes durante a germinação. Analisando-se a Figura 6, confirma-se que o GA induz à síntese das enzimas de degradação de reservas, pela atividade da $\alpha$-amilase, já que ocorre uma síntese de 'novo' 


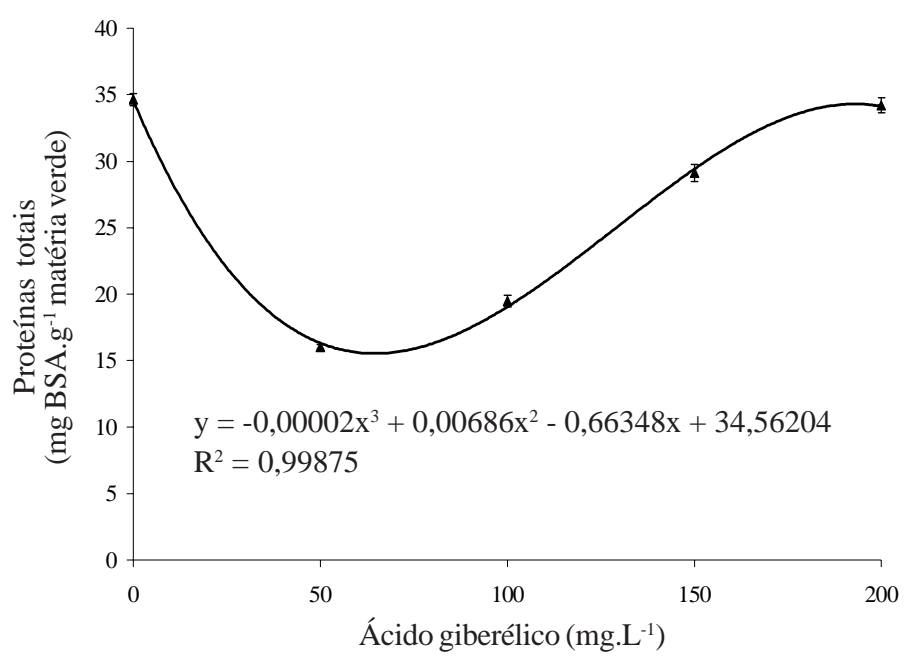

FIG 5. Teor de proteína total de sementes armazenadas de milho super doce, submetidas a doses crescentes de ácido giberélico (Botucatu, 2001).

dessa enzima durante a germinação. Por outro lado observa-se na mesma Figura que o $\mathrm{GA}_{3}$ induziu o aumento da atividade de outras amilases.

A alta degradação de proteínas de reserva associada à alta atividade de $\alpha$-amilase (Figuras 5 e 6), proporcionou um aumento da germinação e vigor das sementes tratadas com $50 \mathrm{mgL}^{-1}$ de $\mathrm{GA}_{3}$ (Figuras 1 e 2). Esses resultados são coerentes com aqueles por Shaw \& Ou-Lee, citados por Das \& SenMandi (1992), trabalhando com sementes de arroz, onde verificaram que a atividade de a-amilase é necessária para a germinação das sementes.

Filner \& Varner (1967) mostraram que a $\alpha$-amilase é sintetizada em resposta ao ácido giberélico produzido pelo embrião e transferido para a camada de aleurona da célula, onde essa enzima é produzida via síntese de novo, promovendo a conversão do amido para açúcar, que é usado no crescimento da plântula.

\section{CONCLUSÃO}

As pré-embebição de sementes de milho de armazenadas em solução de 50mg.L - $^{-1}$ de ácido giberélico, levou à sua maior atividade metabólica e, assim, maior germinação e vigor.

\section{REFERÊNCIAS}

ARAGÃO, C.A.; LIMA, M.W.P.; MORAIS, O.M.; NEVES, M.B.; ONO, E.O.; RODRIGUES, J.D.; BOARO, C.F.S.; NAKAGAWA, J.; CAVARIANI, C. Fitorreguladores na germinação de sementes e

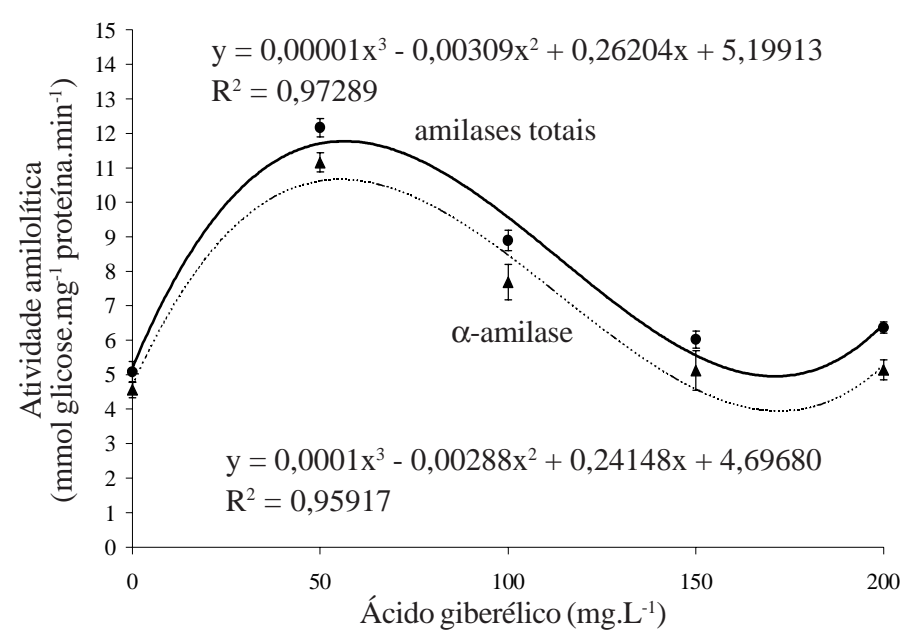

FIG. 6. Atividade de amilases totais e $\alpha$-amilase de sementes armazenadas de milho super doce, submetidas a doses crescentes de ácido giberélico (Botucatu, 2001).

no vigor de plântulas de milho doce. Revista Brasileira de Sementes, Brasília, v.23, n.1, p.62-67, 2001.

BEVILAQUA, G.A.P.; PESKE, S.T.; SANTOS-FILHO, B.G. Desempenho de sementes de arroz irrigado tratadas com regulador de crescimento. I. Efeito na emergência a campo. Revista Brasileira de Sementes, Brasília, v.15, n.1, p.75-80, 1993.

BEVILAQUA, G.A.P.; PESKE, S.T.; SANTOS-FILHO, B.G.; SANTOS, D.S.B. Efeito do tratamento de sementes de cenoura com reguladores de crescimento. Pesquisa Agropecuária Brasileira, Brasília, v.33, n.8, p.1271-1280, 1998.

BRASIL. Ministério da Agricultura e Reforma Agrária. Regras para análise de sementes. Brasília: SNAD/DNDV/CLAV, 1992. 365p.

CARVALHO, N.M. de; NAKAGAWA, J. Sementes: ciência, tecnologia e produção. 3.ed. Campinas: Fundação Cargill, 1988. 424p.

COMISSÃO ESTADUAL DE SEMENTES E MUDAS DE SÃO PAULO. Padrões de sementes de grandes culturas 1999-2000. Campinas, 1999.

CUNHA, R.; CASALI, W.D. Efeito de substâncias reguladoras de crescimento sobre a germinação de sementes de alface (Lactuca sativa L.). Revista Brasileira de Fisiologia Vegetal, Brasília, v.1, n.2, p.121-132, 1989.

DAS, G.; SEN-MANDI, S. Scutellar amilase activity in naturally aged and accelerated aged wheat seeds. Annals of Botany, London, v.69, n.6, p.497-501, 1992.

GUGELMINETTI, L.; YAMAGUCHI, J. PERATA, P.; ALPI, A. Amilolitic activities in cereal seeds under aerobic and anaerobic conditions. Plant Physiology, Rockwille, v.109, n.1, p.1069-1076. 1995.

KHAN, A.A. Incorporation of bioactive chemicals into seeds to alleviate environmental stress. Acta Horticulturae, Wageningen, v.83, p.2255-2264, 1978.

LEONEL, S.; RODRIGUES, J.D. Germinação de sementes de 
limoeiro cravo. In: CONGRESSO BRASILEIRO DE FRUTICULTURA, 14., 1996, Curitiba. Anais... Curitiba: Sociedade Brasileira de Fruticultura, 1996. p.167.

LEVITT, J. Introduction to plant physiology. 2.ed. Saint Louis: The C.V. Mosby Company, 1974. 447p.

LOWRY, O.H.; ROSEBROUGH, N.J.; FARR, A.L.; RANDAL, R.J. Protein measurement with the Folin phenol reagent. Journal of Biological Chemistry, Bethesda. v.193, p.265-275, 1951.

MAYER, A.M.; POLJAKOFF-MAYBER, A. The germination of plants. 4.ed. Oxford: Pergamon Press, 1978. 270p.

McDONALD, M.D.; KHAN, A.A. Acid scarification and protein synthesis during seed germination. Agronomy Journal, Madison, v.2, n.75, p.111-114, 1983.

NAGAO, M.A.; FURUTANI, S.C. Improving germination of papaya seed by density separation, potassium nitrate, and gibberelic acid. HortScience, Alexandria, v.21, n.6, p.1439-1440, 1986.
OLIVEIRA, J.A.; CARVALHO, M.L.M.; VIEIRA, M.G.G.C., VON PINHO, E.V.R. Comportamento de sementes de milho colhidas por diferentes métodos, sob condições de armazém convencional. Ciência e Agrotecnologia, Lavras, v.23, n.2, p.289-302, 1999.

ROSSETO, C.A.V.; CONEGLIAN, R.C.C.; NAKAGAWA, J.; SHIMIZU, M.K.; MARIN, V.A. Germinação de sementes de maracujá-doce (Passiflora alata Dryand) em função de tratamento pré-germinativo. Revista Brasileira de Sementes, Brasília, v.22, n.1, p.247-252, 2000.

SALISBURY, F.B.; ROSS, C.W. Plant physiology, Belmont: Wadsworth, 1991. 682p.

TOLEDO, F.F.; MARCOS FILHO, J. Manual das sementes tecnologia da produção. São Paulo: Agronômica Ceres, 1977. 224p.

VIEIRA, H.D.; SILVA, R.F.; BARROS, R.S. Efeito de substâncias reguladoras de crescimento sobre a germinação de sementes de Braquiarão cv. Marandu. Revista Brasileira de Fisiologia vegetal, Brasília, v.10, n.2, p.143-148, 1998. 